\title{
Maternal Differences and Birth Outcome Disparities: Diversity Within a High-Risk Prenatal Clinic
}

\author{
Melanie Thomas • Anna Spielvogel • Frances Cohen • \\ Susan Fisher-Owens • Naomi Stotland • Betsy Wolfe • \\ Martha Shumway
}

Received: 16 August 2013 /Revised: 26 November 2013 / Accepted: 2 December 2013 /Published online: 18 January 2014

(C) Cobb/NMA Health Institute 2014

\begin{abstract}
Background We examined the influence of race/ethnicity on appointment attendance, maternal psychiatric and medical diagnoses, and birth outcomes within a diverse, low income, high-risk pregnant population to determine whether birth outcome disparities would be lessened in a sample with high biopsychosocial risk across all groups.

Methods Data were retrospectively obtained on all women scheduled for appointments in the San Francisco General Hospital High-Risk Obstetrics clinic during a 3-month period. General linear model and logistic regression procedures were used to examine the associations of race/ethnicity with maternal characteristics, clinic attendance, and birth outcomes.

Results Our sample included 202 maternal-infant pairs (Hispanic, $57 \%$; Black, $16 \%$; Asian, $15 \%$; and White, $12 \%$ ). Racial/ethnic differences were seen in language $(p<0.001)$, gravidity $(p<0.001)$, parity $(p=0.005)$, appointment attendance $(p<0.001)$, diabetes $(p=0.005)$, psychiatric diagnosis $(p=0.02)$, illicit drug use $(p<0.001)$, and smoking $(p<0.001)$. These maternal characteristics, including rate of attendance at specialized prenatal appointments, did not predict birth outcomes with the exception of an association between diabetes and earlier gestational age $(p=0.03)$. By contrast, Black maternal race/ethnicity was associated with
\end{abstract}

\footnotetext{
M. Thomas $(\bowtie) \cdot$ A. Spielvogel $\cdot$ F. Cohen $\cdot$ B. Wolfe

M. Shumway

UCSF Department of Psychiatry, San Francisco, CA, USA

e-mail: melanie.thomas@ucsf.edu

S. Fisher-Owens

UCSF Department of Pediatrics, San Francisco, CA, USA

N. Stotland

UCSF Department of Obstetrics and Gynecology,

San Francisco, CA, USA
}

earlier gestational age at birth $(p=0.004)$ and lower birth weight $(p<0.001)$ compared with Whites.

Conclusions Within a diverse maternal population of high biopsychosocial risk, racial/ethnic disparities in birth outcomes persist. These disparities have implications for infant health trajectory throughout the lifecourse and for intervention implementation in high-risk groups.

Keywords Racial/ethnic disparities · Birth outcomes · Pregnancy $\cdot$ Maternal health $\cdot$ Mental health

\section{Introduction}

Racial/ethnic disparities in adverse birth outcomes in the USA continue [1] despite significant public health attention and increased multidisciplinary efforts $[2,3]$. Adverse birth outcomes include preterm birth (PTB; birth before 37 weeks gestational age) and low birth weight (LBW; birth weight less than 2,500 g). The most documented disparity is the Black/ White gap. Compared with Whites, African American infants are 2.5 times more likely to die in the first year of life; most of this mortality is linked to either PTB and/or LBW [4]. PTB and LBW babies are at risk for a host of negative trajectories including worse developmental outcomes and a greater risk of metabolic and psychiatric illness throughout life [5-8]. Although most studies focus on LBW and PTB infants, smaller infants within the normal weight range may also be at increased risk for cardiovascular disease, diabetes, and mental illness across the life span $[5,9,10]$.

The causes of birth outcome disparities are complex and unclear. Both a purely genetic explanation and the argument that race is simply a proxy for socioeconomic status (SES) have been largely refuted. The infants of foreign-born Black women have birth weights closer to those of US-born Whites than to those born to US-born Blacks [11, 12]. Furthermore, 
across generations, the birth outcomes of Black women get worse with more years spent in the United States [13]. Although women of lower SES have more adverse birth outcomes, racial/ethnic differences remain within all SES levels and, in fact, widen with higher SES [14]. The Hispanic paradox of relatively good birth outcomes among poor Hispanic women further refutes SES as a singular explanation $[15,16]$. Additionally, although racial differences in prenatal care are documented, expansion of insurance coverage and greater rates of early prenatal care have not resulted in better birth outcomes for any group [17-19], indicating that access to care alone will not resolve the disparities.

Myriad other social factors, medical conditions, maternal behaviors, and psychological stressors have been considered as explanations for birth outcome disparities. In spite of racial/ ethnic differences in various biopsychosocial factors among pregnant women, these factors alone do not seem to explain the differences in adverse birth outcomes [20,21]. The effects of maternal stress on birth outcomes have been broadly studied [22-27]. However, studies examining racial differences in perceived stress, mechanisms, biomarkers of stress during pregnancy, and response to stress-related interventions have shown mixed results [28-31]. The theories of "weathering" and "allostatic load" posit that cumulative stress results in premature aging across multiple physiological systems that could explain racial/ethnic disparities across health outcomes $[32,33]$, but empirical evidence is inconclusive. These potential mechanisms are consistent with the theoretical explanation that the social construct of race/ethnicity in the USA results both in greater cumulative stress and greater exposure to particular stressors such as discrimination and trauma which in turn accounts for birth outcome disparities [20, 21, 34, 35].

We are unaware of any studies examining racial/ethnic differences in maternal characteristics and birth outcomes within a high-risk obstetrics clinical setting. Given the unanswered question of the relative contribution of medical, psychological, and social stressors to birth outcome disparities, we wanted to look within a "real world" setting with a high prevalence of these factors among a diverse group of pregnant women. The San Francisco General Hospital High-Risk Obstetrics (SFGH HROB) clinic provides a unique opportunity to conduct this study. All pregnant women who receive care at the clinic are a part of a health care safety net system and thus have relatively low SES, and most have substantial psychosocial stressors often including trauma exposure over the life course [36, 37]. This clinic also provides rich racial/ethnic diversity allowing for inclusion and comparison of groups beyond the most documented Black/White disparities. We hypothesized that within this setting, racial/ethnic disparities might be lessened since all women were at risk. In particular, we theorized that the gap usually seen between Black and White birth outcomes would decrease. We further hypothesized that inadequate prenatal care utilization (i.e., missed appointments) and/or comorbid medical and psychiatric illness would be associated with more adverse birth outcomes across all groups in this high-risk population.

\section{Methods}

Study Setting and Population

This retrospective, chart review study was conducted using data from the SFGH HROB clinic. SFGH functions as a safety net healthcare facility in a diverse, urban setting in Northern California. The multidisciplinary SFGH HROB clinic receives referrals from community-based prenatal providers throughout San Francisco County. Patients are referred for both psychiatric and obstetric concerns that require specialist care. Within the clinic, obstetricians, psychiatrists, nurses, nutritionists, psychologists, and social workers provide integrated health care and multidisciplinary rounds occur weekly to discuss patient care plans.

\section{Chart Abstraction and Variables}

Women were eligible for inclusion if they were referred to the Obstetric or Psychiatry specialties of the clinic from October through December 2008 regardless of clinic appointment attendance. Patient name and date of birth from the referral list were matched to the electronic medical record (EMR). Using this record, chart abstraction of demographic and clinical information was performed by two research assistants. To examine the relationship between maternal characteristics and birth outcomes, our final sample was limited to women who had live, singleton infants with medical information available in the EMR.

Maternal demographic characteristics abstracted from the EMR included race/ethnicity, age, and English language usage. Obstetric data included gravidity, parity, diagnosis of gestational or other diabetes during pregnancy, and delivery by Cesarean section. Other information collected on maternal health and health-related behaviors included current or past psychiatric diagnoses, obesity, hypertension, smoking history, and illicit drug use. Data on health care use included specialty of referral (Obstetrics or Psychiatry), rate of Obstetric appointment attendance in the HROB clinic, and number of days spent in the hospital at delivery. For the infants, we abstracted information on sex, gestational age at birth (as recorded by clinicians using last menstrual period and ultrasound dating), and birth weight.

Approval for this study was obtained from the Institutional Review Boards at the University of California San Francisco and at San Francisco General Hospital. 


\section{Statistical Analyses}

We used Chi-square tests for categorical variables and general linear models, with post hoc tests for pairwise comparisons, for continuous variables. To maintain consistency in analysis for all pairwise comparisons, White was used as the referent race/ethnicity category. Simultaneous multiple linear regression was used to examine relationships between maternal and infant characteristics and continuous measures of birth weight and gestational age at birth. For dichotomous indicators of LBW and PTB, simultaneous multiple logistic regression was used. In regression models, theoretically relevant variables that differed significantly by race/ethnicity were included in our analysis of maternal and infant characteristics. All statistical analyses were conducted using SAS 9.2.

\section{Results}

Two hundred sixty-six women were referred to the SFGH HROB clinic during the 3-month study period. Four women were dropped from analysis because their race/ethnicity was recorded as other than White, Black, Hispanic, or Asian. Forty-one of the remaining 262 women had no record of delivery at SFGH (delivery elsewhere (6), terminated pregnancy (11), no information about delivery or termination (24)). Of these 221 women with documented delivery at SFGH, there were 6 sets of twins, 2 stillbirths, and 11 otherwise eligible mother-infant pairs without a recorded birth weight. This resulted in 202 mother-singleton-infant pairs available for analysis.

Table 1 shows maternal demographic and clinical characteristics by race/ethnicity. The average age was 29.6 years. Mean gravidity of women was 3.5 and mean parity was 1.4. Our sample showed considerable racial/ethnic diversity representative of the clinic overall, with the majority of women identified as Hispanic (57\%) and non-English speaking (55\%). White women (12\%), Black women (16\%), and Asian women (15\%) were equally represented. Overall, maternal clinical risk factors known to influence birth weight and other adverse birth outcomes were prevalent as would be expected in this setting. Medical and psychiatric risk factors included high rates of diabetes ( $42 \% ; 18 \%$ pre-existing, $82 \%$ gestational), obesity ( $22 \%$ ), hypertension ( $27 \%$ ), current or previous psychiatric diagnoses $(37 \%$; including mood, anxiety, and psychotic disorders), history of illicit drug use (19\%), and history of smoking $(10 \%)$. The majority of women (73\%) were referred for Obstetrics appointments only, $17 \%$ were referred for Psychiatry only, and $10 \%$ were referred for both.

There were no significant differences among racial/ethnic groups for age, type of referral to the HROB clinic, obesity, hypertension, number of days in the hospital, or rate of
Cesarean section. For all other maternal characteristics measured, racial/ethnic differences were found. Black women had the highest gravidity (5.3) and parity (2.1) and Asian women had the lowest gravidity (2.7) and parity (0.9). White women were less likely to attend their Obstetric clinic appointments ( $45 \%$ attended none) compared with women who were Black (24\%), Hispanic (12\%), or Asian (7\%). Half of the Hispanic and Asian women in our sample had a diagnosis of diabetes, contrasted with $28 \%$ of Black women and $13 \%$ of White women. Prevalence of psychiatric diagnosis was higher among White (54 \%) and Black (53\%) women and lower for Hispanics ( $32 \%$ ) and Asians (23\%). Racial/ethnic differences in history of illicit drug use were substantial, with the highest rates among Whites (63\%) and Blacks (56\%) and much lower rates for Hispanic (3\%) and Asian (7\%) women. A similar pattern was seen for smoking history with highest rates among Whites (42\%) followed by Blacks $(25 \%)$ and significantly different from Asians (3\%) and Hispanics (2\%).

Table 2 shows infant outcomes by maternal race/ethnicity. Women in our sample gave birth to a greater percentage of males $(58 \%)$ than females ( $42 \% ; p=0.02)$. The mean gestational age at birth was 38.5 weeks and the average birth weight was $3,282 \mathrm{~g}$. Overall rates of adverse birth outcomes were $15 \%$ PTB, $10 \%$ LBW, and $7 \%$ high birth weight (HBW; defined as $>4,000 \mathrm{~g}$ ). Racial/ethnic differences in adverse birth outcomes were not significant, although Black women had the highest rates of PTB (23\%) and LBW (22\%), and no HBWs. White women had the lowest rates of LBW (4\%), the highest rates of HBW (21\%), and no PTBs. Continuous measures of birth weight and gestational age did show racial/ethnic differences. Post hoc comparisons showed the Black/White difference was significant for both birth weight $(p=0.002)$ and gestational age $(p=0.01)$ with infants of Black mothers weighing less and being born earlier than Whites. Asian and Hispanic infants had gestational ages and birth weights in between those of their White and Black counterparts; their values were not significantly different from Whites.

Table 3 reports the results of two separate linear regression models examining associations between maternal characteristics on gestational age and birth weight as continuous variables. Since female infants had lower birth weights than males $(p=0.04)$, we included infant sex in these analyses. In each model, we also included maternal characteristics that showed racial/ethnic differences (language, parity, diabetes, psychiatric diagnosis, illicit drug use, and smoking history). Black race/ethnicity was the only maternal characteristic associated with birth weight $(p<0.001)$; the birth weights of Black infants were significantly lower than those of Whites. Other races/ ethnicities did not show significant differences from Whites. When infants born earlier than 37 weeks of gestational age were removed from the model, the average birth weight of Black infants was still significantly less than Whites $(p=0.02)$, 
Table 1 Maternal characteristics by race/ethnicity

\begin{tabular}{|c|c|c|c|c|c|c|}
\hline Characteristic & $\begin{array}{l}\text { Total } \\
(N=202)\end{array}$ & $\begin{array}{l}\text { White }(n=24 \\
(12 \%))\end{array}$ & $\begin{array}{l}\text { Black }(n=32 \\
(16 \%))\end{array}$ & $\begin{array}{l}\text { Hispanic }(n=116 \\
(57 \%))\end{array}$ & $\begin{array}{l}\text { Asian }(n=30 \\
(15 \%))\end{array}$ & $p$ \\
\hline Age (years, mean (SD)) & $29.6(6.0)$ & $28.9(5.1)$ & $29.3(6.9)$ & $29.4(5.9)$ & $31.4(5.9)$ & 0.34 \\
\hline English speaking (\%) & 45 & 96 & 100 & 20 & 43 & $<0.001^{\mathrm{b}, \mathrm{c}}$ \\
\hline Gravidity (mean (SD)) & $3.5(2.5)$ & $4.4(3.0)$ & $5.3(3.0)$ & $3.0(2.2)$ & $2.7(1.6)$ & $<0.001^{\mathrm{c}}$ \\
\hline Parity (mean (SD)) & $1.4(1.4)$ & $1.4(1.3)$ & $2.1(1.9)$ & $1.4(1.2)$ & $0.9(1.0)$ & 0.005 \\
\hline Referral type (\%) & & & & & & 0.51 \\
\hline OB only & 73 & 67 & 72 & 71 & 87 & \\
\hline Psych only & 17 & 17 & 22 & 19 & 3 & \\
\hline Both & 10 & 17 & 6 & 10 & 10 & \\
\hline OB appointment attendance rate (\%) & & & & & & $<0.001^{\mathrm{b}, \mathrm{c}}$ \\
\hline None & 17 & 45 & 24 & 12 & 7 & \\
\hline Some & 33 & 25 & 48 & 33 & 24 & \\
\hline All & 50 & 30 & 28 & 55 & 69 & \\
\hline Diabetes $(\%)$ & 42 & 13 & 28 & 50 & 50 & $0.005^{\mathrm{b}, \mathrm{c}}$ \\
\hline Obesity (\%) & 22 & 33 & 28 & 22 & 7 & 0.12 \\
\hline Hypertension (\%) & 27 & 33 & 44 & 23 & 20 & 0.10 \\
\hline Psychiatric diagnosis (\%) & 37 & 54 & 53 & 32 & 23 & $0.02^{\mathrm{b}, \mathrm{c}}$ \\
\hline Illicit drug use (\%) & 19 & 63 & 56 & 4 & 7 & $<0.001^{\mathrm{b}, \mathrm{c}}$ \\
\hline Smoking (\%) & 10 & 42 & 25 & 2 & 3 & $<0.001^{\mathrm{b}, \mathrm{c}}$ \\
\hline $\begin{array}{l}\text { Number of days in hospital after delivery } \\
\text { (mean (SD)) }\end{array}$ & 3.4 & 3.1 & 4.1 & 3.2 & 3.5 & 0.07 \\
\hline Cesarean section $(\%)$ & 29 & 29 & 34 & 27 & 33 & 0.80 \\
\hline
\end{tabular}

Logistic regression was used to compare racial/ethnic groups on dichotomous, ordinal, and nominal variables. General linear models were used to compare racial/ethnic groups on continuous variables

${ }^{\text {a }}$ Blacks differ from Whites at $p<0.05$

${ }^{\mathrm{b}}$ Hispanics differ from Whites at $p<0.05$

${ }^{\mathrm{c}}$ Asians differ from Whites at $p<0.05$

Table 2 Infant outcomes by maternal race/ethnicity

\begin{tabular}{|c|c|c|c|c|c|c|}
\hline Characteristic & $\begin{array}{l}\text { Total } \\
(N=202)\end{array}$ & $\begin{array}{l}\text { White }(n=24 \\
(12 \%))\end{array}$ & $\begin{array}{l}\text { Black }(n=32 \\
(16 \%))\end{array}$ & $\begin{array}{l}\text { Hispanic }(n=116 \\
(57 \%))\end{array}$ & $\begin{array}{l}\text { Asian }(n=30 \\
(15 \%))\end{array}$ & $P$ \\
\hline Infant sex $(\%)$ & & & & & & 0.33 \\
\hline Female & 42 & 50 & 53 & 37 & 40 & \\
\hline Male & 58 & 50 & 47 & 63 & 60 & \\
\hline $\begin{array}{l}\text { Gestational age at birth } \\
\text { (weeks, mean (SD)) }\end{array}$ & $38.5(1.9)$ & $39.4(1.2)$ & $37.7(2.6)$ & $38.4(1.7)$ & $38.7(2.3)$ & $0.01^{\mathrm{a}}$ \\
\hline Preterm birth ${ }^{\mathrm{d}}(\%)$ & 15 & 0 & 23 & 16 & 13 & 0.31 \\
\hline $\begin{array}{l}\text { Birth weight (grams, mean } \\
\text { (SD)) }\end{array}$ & $3,282(605.9)$ & $3,593(641.2)$ & $2,974(691.1)$ & $3,299(564.9)$ & $3,295(506.2)$ & $0.002^{\mathrm{a}}$ \\
\hline Low birth weight ${ }^{\mathrm{e}}(\%)$ & 10 & 4 & 22 & 9 & 10 & 0.15 \\
\hline High birth weight ${ }^{\mathrm{f}}(\%)$ & 7 & 21 & 0 & 7 & 3 & 0.07 \\
\hline
\end{tabular}

Logistic regression was used to compare racial/ethnic groups on dichotomous, ordinal, and nominal variables. General linear models were used to compare racial/ethnic groups on continuous variables

${ }^{\text {a }}$ Blacks differ from Whites at $p<0.05$

${ }^{\mathrm{b}}$ Hispanics differ from Whites at $p<0.05$

${ }^{\mathrm{c}}$ Asians differ from Whites at $p<0.05$

${ }^{\mathrm{d}}$ Pre-term birth $=$ delivery before 37 weeks gestation

${ }^{\mathrm{e}}$ Low birth weight $=$ less than $2,500 \mathrm{~g}$

${ }^{\mathrm{f}} \mathrm{High}$ birth weight $=$ greater than $4,000 \mathrm{~g}$ 
Table 3 Regression analyses of birth outcomes with maternal characteristics and infant sex

\begin{tabular}{|c|c|c|c|c|}
\hline & Beta/estimate & $t$ value & $p$ & $95 \%$ confidence limits \\
\hline \multicolumn{5}{|l|}{ Birthweight } \\
\hline \multicolumn{5}{|c|}{ Race/ethnicity (referent=white) } \\
\hline Black & -603.02 & -3.71 & $<0.001$ & $-923.65,-282.40$ \\
\hline Hispanic & -227.68 & -1.26 & 0.21 & $-583.70,128.33$ \\
\hline Asian & -209.89 & -1.10 & 0.27 & $-586.69,166.90$ \\
\hline English language & 42.38 & 0.37 & 0.71 & $-184.83,269.59$ \\
\hline Parity & 51.32 & 1.59 & 0.11 & $-12.50,115.14$ \\
\hline Diabetes & -18.13 & -0.20 & 0.84 & $-193.39,157.13$ \\
\hline Psychiatric diagnosis & 56.89 & 0.62 & 0.54 & $-125.33,239.11$ \\
\hline Illicit drug use & 45.83 & 0.31 & 0.75 & $-241.25,332.90$ \\
\hline Smoking history & -166.31 & -1.06 & 0.29 & $-475.72,143.10$ \\
\hline Infant sex (female) & -175.10 & -2.09 & 0.04 & $-340.24,-9.96$ \\
\hline \multicolumn{5}{|l|}{ Gestational age } \\
\hline \multicolumn{5}{|c|}{ Race/ethnicity (referent=white) } \\
\hline Black & -1.59 & -2.95 & 0.004 & $-2.65,-0.53$ \\
\hline Hispanic & -0.66 & -1.11 & 0.27 & $-1.84,0.51$ \\
\hline Asian & -0.38 & -0.60 & 0.55 & $-1.62,0.86$ \\
\hline English language & -0.19 & -0.51 & 0.61 & $-0.94,0.56$ \\
\hline Parity & -0.004 & -0.03 & 0.97 & $-0.22,0.21$ \\
\hline Diabetes & -0.64 & -2.18 & 0.03 & $-1.22,-0.06$ \\
\hline Psychiatric diagnosis & 0.14 & 0.47 & 0.64 & $-0.46,0.75$ \\
\hline Illicit drug use & 0.62 & 1.27 & 0.20 & $-0.34,1.58$ \\
\hline Smoking history & -0.39 & -0.76 & 0.45 & $-1.41,0.63$ \\
\hline Infant sex (female) & -0.28 & -1.00 & 0.32 & $-0.82,0.27$ \\
\hline
\end{tabular}

confirming that differences between these groups remained when PTBs were excluded. Furthermore, when gestational age was included as a covariate in the model for birth weight, Black infants remained smaller than White infants $(p=0.02)$. For gestational age, maternal diabetes $(p=0.03)$ and Black race/ethnicity ( $p=0.004)$ were significant predictors. Mothers with diabetes delivered infants at an earlier gestational age. Black infants were born at an earlier gestational age than White infants whereas Asian and Hispanic infants did not differ from White infants on this variable. Both models explained only $10 \%$ of the variance in the outcomes.

To test the effect of prenatal care, for each outcome of birth weight and gestational age, we examined regression models including a variable for the percent of Obstetrics appointments attended. Although this eliminated 37 women who were only referred to Psychiatry, we wanted to account for a possible influence of appointment attendance on birth outcomes. With the smaller sample and Obstetrics appointment attendance included in the model, the significant associations for Black race/ethnicity remained for both outcomes (birth weight, $p<0.001$; gestational age, $p=0.008$ ), indicating that lack of attendance at prenatal appointments did not account for the disparity. We also examined the effects on birth weight while excluding HBW babies to assure that the high rates of White
HBW babies did not skew our results. In the model excluding HBW babies, the association with Black race/ethnicity and lower birth weight remained significant $(p=0.01)$. In similar logistic regression analyses examining PTB and LBW as categorical outcomes, no statistically significant relationships between maternal characteristics and infant outcomes were observed. For both types of adverse outcomes, Black race/ethnicity trended toward significance $(\mathrm{PTB}, p=0.07$; LBW, $p=0.09$ ).

We also conducted regression models with the continuous variables of birth weight and gestational age to look at various subgroups in our sample: (1) women with and without diabetes and (2) Hispanic women only. Given the high rates of diabetes in our sample and the potential influence of diabetes on birth outcomes, we looked at regression models for each outcome after splitting our sample into women with and without diabetes. For women without diabetes, the significant associations between Black race/ethnicity remained for both outcomes (birth weight, $p=0.002$; gestational age, $p=0.008$ ). However, in the regression models restricted to women with diabetes, there were no longer any significant associations between maternal characteristics, infant sex, and birth outcomes. We also conducted the analyses restricted to Hispanic women, since they were the majority group. These regression 
models showed nonsignificant results for all variables. For all regression models not shown, data is available on request.

\section{Discussion}

In our diverse "real world" examination of birth outcomes among women with high-risk pregnancies in a healthcare safety net setting, we have three primary findings: (1) high rates of maternal medical and psychiatric illness as anticipated, but the overall rate of adverse birth outcomes was lower than expected given the risk profile of our sample; (2) significant racial/ethnic differences in the maternal characteristics measured; and (3) Black/White differences in birth weight and gestational age despite the similarities in maternal risk profiles for these groups.

Our sample showed significant maternal morbidity as would be expected from a high-risk sample. Specifically, $42 \%$ of women had diabetes and the majority of these (82\%) had gestational diabetes mellitus (GDM). Thus women with GDM constituted $35 \%$ of our entire sample, a rate substantially higher than the 3-5\% overall incidence of GDM among pregnant women [38]. Additionally, $37 \%$ of women in our sample had a documented current or past psychiatric diagnosis and $19 \%$ a current or past history of illicit drug use, as compared with reported rates of prenatal depression from 6.5 to $18.4 \%$ [39] and a $4.7 \%$ prevalence of illicit drug use among pregnant women [40]. In spite of the substantial maternal morbidities within our sample, overall rates of PTB $(14.5 \%)$ and LBW $(10.4 \%)$ were not much higher than the nationally reported 2008 rates (12.3 and $8.18 \%$ ), respectively [1]. As the majority of women in our sample are Hispanic, possible explanations for the overall relatively good birth outcomes may be the "Hispanic paradox" $[15,16,41]$ and/or particular efforts made by the SFGH clinic to serve the Spanish-speaking population (e.g., provider language concordance and other outreach programs). We could not explore issues of nativity and acculturation because these data were not available (but have been shown to interact differently for various racial/ethnic groups in predicting birth outcomes) [41, 42]. Another surprising finding was the greater number of male births than females within our sample. A full exploration of infant-sex ratios is well outside the scope of this study; however, other studies on infant sex ratios have attributed births of more girls to maternal stress [43] and births of more boys to maternal diabetes [44], two maternal characteristics prevalent in our sample.

For many maternal characteristics (appointment attendance, diabetes, psychiatric illness, drug use, and smoking), our data showed a different pattern for Blacks and Whites compared with Hispanic and Asian women. We are not aware of another study in a high-risk population that has documented this pattern for such a variety of characteristics, but our findings are consistent with some previous studies. The finding of equivalent rates of drug use among White and Black women is consistent with other studies $[45,46]$. Less drug use and smoking among the Asian and Hispanic women is consistent with studies showing more positive health-related behaviors and less drug use among foreign-born pregnant women in the USA $[47,48]$. Although we did not have access to nativity or immigration status data, given the percentage of non-English speaking women in both our Asian and Hispanic groups, it is likely that many of these women were recent immigrants.

The difference in diabetes prevalence between racial/ethnic groups is similar to previously reported patterns, with nonWhite women having higher rates than White women [49, 50]. When we restricted our regression model predicting birth outcomes to only the women in our sample with diabetes, all associations between other maternal characteristics and birth outcomes disappeared. This is consistent with other findings that diabetes during pregnancy may impact maternal and infant outcomes disparately for different racial/ethnic groups; for example, chronic diabetes may increase risk for LBW among Whites, Asians, and Hispanics, but does not appear to have this effect for Blacks [50].

In spite of the similar maternal risk profiles between Blacks and Whites in our high-risk sample, the well-known US Black/White gap in birth outcomes remained. Black race/ethnicity and female infant sex were the only variables significantly associated with birth weight after accounting for other known maternal risk factors including diabetes, psychiatric illness, illicit drug use, and smoking. Black women in our sample had infants with a mean birth weight more than $600 \mathrm{~g}$ lower than their White counterparts. Although many studies emphasize the adverse effects of PTB and LBW, there is evidence to support that over the lifecourse birth weight is inversely associated with increased risk for diabetes [10], mental illness [5], and coronary disease mortality [9] even within the normal birth weight range. Furthermore, Black race/ethnicity and maternal diabetes were the only variables significantly associated with gestational age. On average, infants of Black mothers were born almost 2 weeks earlier than Whites. Although not statistically significant, adverse birth outcomes of PTB and LBW were greatest for Black women in our sample. In terms of low appointment attendance, smoking, rates of illicit drug use, and psychiatric diagnoses, Black and White women had similar maternal risk profiles. In fact, White women were the most likely of all groups to use illicit drugs and smoke tobacco and the least likely to attend their OB appointments. Still, within our highrisk sample, the Black/White gap in birth outcomes remainswith Black infants being born earlier and weighing less than Whites. Although not measured in our study, a possible contributing factor includes the greater likelihood for Black women to have experienced racially based discrimination 
compared with Whites [51]. The relationship between racial discrimination and adverse birth outcomes has been discussed elsewhere $[29,52,53]$; however, the mechanisms for such an effect remain unclear.

Our study has several limitations. As a retrospective chart review, the study is limited to data available within the EMR and for women who delivered at SFGH. Therefore, we could not obtain information about additional biopsychosocial factors likely to influence birth outcomes including individual measures of SES, pre-pregnancy BMI, nutritional status, gestational weight gain, experiences of discrimination, details of psychiatric history, or maternal early life experiences. Second, additional information about nativity and immigration status would be valuable to further examine the Hispanic majority in our sample. Finally, our study focuses on a specific clinic so results may not be generalizable to other clinic settings or pregnant women overall.

Our study also has significant strengths. To our knowledge, studies of the well-known racial/ethnic birth outcome disparities in the USA have not previously been carried out in a high-risk clinic population with many maternal risk factors. Our results are strengthened by our attention to both LBW and PTB as related yet distinct adverse birth outcomes and the examination of birth weight and gestational age as continuous variables [54]. Although the sample may not be generalizable, the findings from this clinical setting can inform future work. Our study not only highlights Black/White birth outcome disparities but also has the advantage of substantial representation of other racial/ethnic groups, including a Hispanic majority, allowing comparisons.

Further work is needed to identify, understand, and interrupt factors in the matrix of risk that contribute to ongoing birth outcome disparities. Additional research is needed in three areas — over the life course $[21,55,56]$, in the broader ecological environment $[57,58]$, and within the community $[59,60]$. The life course approach, with particular attention to cumulative effects of poverty and discrimination, may predict more accurately which women are at risk for adverse birth outcomes and allow us to better focus efforts for interventions. As $\mathrm{Lu}$ and Halfon carefully detail and our study replicates, risk factors measured only during pregnancy do not adequately explain disparities [21], and a broader look at early experiences and cumulative stressors is warranted. Future research should also focus on the mechanisms of racial/ethnic differences in birth outcomes including interaction effects of race/ethnicity with risk factors and other predictors. Our results illustrate that the availability of healthcare alone- even multidisciplinary, innovative prenatal care targeted to highrisk pregnancies - will not be sufficient to eliminate disparities. Our study adds to the growing literature documenting that reducing disparities in birth outcomes is a complex problem that will require complex solutions $[2,3,18,61,62]$. Interventions aimed solely at individual behaviors are only one small piece of the whole picture, and future work should investigate how to appropriately tailor screening and interventions to the specific needs of different racial/ethnic groups within both community and healthcare settings.

\section{References}

1. Martin JA, Hamilton BE, Sutton PD, Ventura SJ, Mathews TJ, Osterman MJ. Births: final data for 2008. Natl Vital Stat Rep. 2010;59(1):3-71.

2. Ashton DM, Lawrence 3rd HC, Adams 3rd NL, Fleischman AR. Surgeon general's conference on the prevention of preterm birth. Obstet Gynecol. 2009;113(4):925-30.

3. Damus K. Prevention of preterm birth: a renewed national priority. Curr Opin Obstet Gynecol. 2008;20(6):590-6.

4. Hauck FR, Tanabe KO, Moon RY. Racial and ethnic disparities in infant mortality. Semin Perinatol. 2011;35(4):209-20.

5. Abel KM, Wicks S, Susser ES, et al. Birth weight, schizophrenia, and adult mental disorder: is risk confined to the smallest babies? Arch Gen Psychiatry. 2010;67(9):923-30.

6. Barker DJ. Adult consequences of fetal growth restriction. Clin Obstet Gynecol. 2006;49(2):270-83.

7. Gillman MW. Developmental origins of health and disease. N Engl J Med. 2005;353(17):1848-50.

8. Johnson RC, Schoeni RF. Early-life origins of adult disease: national longitudinal population-based study of the United States. Am J Public Health. 2011;101(12):2317-24.

9. Godfrey KM, Barker DJ. Fetal nutrition and adult disease. Am J Clin Nutr. 2000;71(5 Suppl):1344S-52S.

10. Whincup PH, Kaye SJ, Owen CG, et al. Birth weight and risk of type 2 diabetes: a systematic review. JAMA. 2008;300(24):2886-97.

11. David RJ, Collins Jr JW. Differing birth weight among infants of U.S.-born blacks, African-born blacks, and U.S.-born whites. N Engl J Med. 1997;337(17):1209-14.

12. Howard DL, Marshall SS, Kaufman JS, Savitz DA. Variations in low birth weight and preterm delivery among blacks in relation to ancestry and nativity: New York City, 1998-2002. Pediatrics. 2006;118(5): e1399-405.

13. Collins Jr JW, Wu SY, David RJ. Differing intergenerational birth weights among the descendants of US-born and foreign-born Whites and African Americans in Illinois. Am J Epidemiol. 2002;155(3):210-6.

14. Blumenshine P, Egerter S, Barclay CJ, Cubbin C, Braveman PA. Socioeconomic disparities in adverse birth outcomes: a systematic review. Am J Prev Med. 2010;39(3):263-72.

15. Acevedo-Garcia D, Soobader MJ, Berkman LF. The differential effect of foreign-born status on low birth weight by race/ethnicity and education. Pediatrics. 2005;115(1):e20-30.

16. Page RL. Positive pregnancy outcomes in Mexican immigrants: what can we learn? J Obstet Gynecol Neonatal Nurs. 2004;33(6):783-90.

17. Bryant AS, Worjoloh A, Caughey AB, Washington AE. Racial/ethnic disparities in obstetric outcomes and care: prevalence and determinants. Am J Obstet Gynecol. 2010;202(4):335-43.

18. Krans EE, Davis MM. Preventing low birthweight: 25 years, prenatal risk, and the failure to reinvent prenatal care. Am J Obstet Gynecol. 2011;206(5):398-403.

19. Ruwe M, Capitman J, Bengiamin M, Soto T. A systematic review and meta-analysis of racial disparities in prenatal care in California: how much? Does insurance matter? Soc Work Public Health. 2010;25(6):550-71.

20. Giscombe CL, Lobel M. Explaining disproportionately high rates of adverse birth outcomes among African Americans: the impact of 
stress, racism, and related factors in pregnancy. Psychol Bull. 2005;131(5):662-83.

21. Lu MC, Halfon N. Racial and ethnic disparities in birth outcomes: a life-course perspective. Matern Child Health J. 2003;7(1):13-30.

22. Dunkel Schetter C. Psychological science on pregnancy: stress processes, biopsychosocial models, and emerging research issues. Annu Rev Psychol. 2011;62:531-58.

23. Dunkel Schetter C, Tanner L. Anxiety, depression and stress in pregnancy: implications for mothers, children, research, and practice. Curr Opin Psychiatry. 2012;25(2):141-8.

24. Giurgescu C, McFarlin BL, Lomax J, Craddock C, Albrecht A. Racial discrimination and the black-white gap in adverse birth outcomes: a review. J Midwifery Womens Health. 2011;56(4):362-70.

25. Glynn LM, Schetter CD, Hobel CJ, Sandman CA. Pattern of perceived stress and anxiety in pregnancy predicts preterm birth. Health Psychol. 2008;27(1):43-51.

26. Hilmert CJ, Schetter CD, Dominguez TP, et al. Stress and blood pressure during pregnancy: racial differences and associations with birthweight. Psychosom Med. 2008;70(1):57-64.

27. Lobel M, Cannella DL, Graham JE, DeVincent C, Schneider J, Meyer BA. Pregnancy-specific stress, prenatal health behaviors, and birth outcomes. Health Psychol. 2008;27(5):604-15.

28. Chen Y, Holzman C, Chung H, Senagore P, Talge NM, Siler-Khodr T. Levels of maternal serum corticotropin-releasing hormone $(\mathrm{CRH})$ at midpregnancy in relation to maternal characteristics. Psychoneuroendocrinology. 2010;35(6):820-32.

29. Dominguez TP, Dunkel-Schetter C, Glynn LM, Hobel C, Sandman CA. Racial differences in birth outcomes: the role of general, pregnancy, and racism stress. Health Psychol. 2008;27(2):194-203.

30. Jallo N, Bourguignon C, Taylor AG, Ruiz J, Goehler L. The biobehavioral effects of relaxation guided imagery on maternal stress. Adv Mind Body Med. 2009;24(4):12-22.

31. Menon R, Arora CP, Hobel CJ, Fortunato SJ. Corticotrophinreleasing hormone in lipopolysaccharide-stimulated term fetal membranes and amniotic fluid from term and preterm birth in African Americans and Caucasians. Reprod Sci. 2008;15(5):477-83.

32. Geronimus AT. Understanding and eliminating racial inequalities in women's health in the United States: the role of the weathering conceptual framework. J Am Med Womens Assoc. 2001;56(4): 133-6. 149-150.

33. McEwen BS. Stress, adaptation, and disease. Allostasis and allostatic load. Ann N Y Acad Sci. 1998;840:33-44.

34. Dominguez TP. Adverse birth outcomes in African American women: the social context of persistent reproductive disadvantage. Soc Work Public Health. 2011;26(1):3-16.

35. Rosenthal L, Lobel M. Explaining racial disparities in adverse birth outcomes: unique sources of stress for Black American women. Soc Sci Med. 2011;72(6):977-83.

36. Alvidrez J, Azocar F. Distressed women's clinic patients: preferences for mental health treatments and perceived obstacles. Gen Hosp Psychiatry. 1999;21(5):340-7.

37. Miranda J, Azocar F, Komaromy M, Golding JM. Unmet mental health needs of women in public-sector gynecologic clinics. Am J Obstet Gynecol. 1998;178(2):212-7.

38. Ben-Haroush A, Yogev Y, Hod M. Epidemiology of gestational diabetes mellitus and its association with type 2 diabetes. Diabet Med. 2004;21(2):103-13.

39. Gavin NI, Gaynes BN, Lohr KN, Meltzer-Brody S, Gartlehner G, Swinson T. Perinatal depression: a systematic review of prevalence and incidence. Obstet Gynecol. 2005;106(5 Pt 1): 1071-83.

40. Havens JR, Simmons LA, Shannon LM, Hansen WF. Factors associated with substance use during pregnancy: results from a national sample. Drug Alcohol Depend. 2009;99(1-3):89-95.

41. Brown HL, Chireau MV, Jallah Y, Howard D. The "Hispanic paradox": an investigation of racial disparity in pregnancy outcomes at a tertiary care medical center. Am J Obstet Gynecol. Aug 2007;197(2): 197 e191-97; discussion 197 e197-199.

42. Osypuk TL, Bates LM, Acevedo-Garcia D. Another Mexican birthweight paradox? The role of residential enclaves and neighborhood poverty in the birthweight of Mexican-origin infants. Soc Sci Med. 2010;70(4):550-60.

43. Catalano R, Ahern J, Bruckner T, Anderson E, Saxton K. Genderspecific selection in utero among contemporary human birth cohorts. Paediatr Perinat Epidemiol. 2009;23(3):273-8.

44. Ehrlich SF, Eskenazi B, Hedderson MM, Ferrara A. Sex ratio variations among the offspring of women with diabetes in pregnancy. Diabet Med. 2012;29(9):e273-8.

45. Chasnoff IJ, Landress HJ, Barrett ME. The prevalence of illicit-drug or alcohol use during pregnancy and discrepancies in mandatory reporting in Pinellas County, Florida. N Engl J Med. 1990;322(17): $1202-6$.

46. Hans SL. Demographic and psychosocial characteristics of substance-abusing pregnant women. Clin Perinatol. 1999;26(1): $55-74$.

47. Callister LC, Birkhead A. Acculturation and perinatal outcomes in Mexican immigrant childbearing women: an integrative review. J Perinat Neonatal Nurs. 2002;16(3):22-38.

48. Elo IT, Culhane JF. Variations in health and health behaviors by nativity among pregnant Black women in Philadelphia. Am J Public Health. 2010;100(11):2185-92.

49. Lawrence JM, Contreras R, Chen W, Sacks DA. Trends in the prevalence of preexisting diabetes and gestational diabetes mellitus among a racially/ethnically diverse population of pregnant women, 1999-2005. Diabetes Care. 2008;31(5):899-904.

50. Rosenberg TJ, Garbers S, Lipkind H, Chiasson MA. Maternal obesity and diabetes as risk factors for adverse pregnancy outcomes: differences among $4 \mathrm{racial} / \mathrm{ethnic}$ groups. Am J Public Health. 2005;95(9): $1545-51$.

51. Williams DR, John DA, Oyserman D, Sonnega J, Mohammed SA, Jackson JS. Research on discrimination and health: an exploratory study of unresolved conceptual and measurement issues. Am J Public Health. 2012;102(5):975-8.

52. Dominguez TP. Race, racism, and racial disparities in adverse birth outcomes. Clin Obstet Gynecol. 2008;51(2):360-70.

53. Nuru-Jeter A, Dominguez TP, Hammond WP, et al. "It's the skin you're in": African-American women talk about their experiences of racism. an exploratory study to develop measures of racism for birth outcome studies. Matern Child Health J. 2009;13(1):29-39.

54. Oken E, Kleinman KP, Rich-Edwards J, Gillman MW. A nearly continuous measure of birth weight for gestational age using a United States national reference. BMC Pediatr. 2003;3:6.

55. Gee GC, Walsemann KM, Brondolo E. A life course perspective on how racism may be related to health inequities. Am J Public Health. 2012;102(5):967-74.

56. Pies C, Parthasarathy P, Posner SF. Integrating the life course perspective into a local maternal and child health program. Matern Child Health J. 2012;16(3):649-55.

57. Alio AP, Richman AR, Clayton HB, Jeffers DF, Wathington DJ, Salihu HM. An ecological approach to understanding black-white disparities in perinatal mortality. Matern Child Health J. 2010;14(4): 557-66.

58. Krieger N. Methods for the scientific study of discrimination and health: an ecosocial approach. Am J Public Health. 2012;102(5): 936-44.

59. Griffith DM, Allen JO, DeLoney EH, et al. Community-based organizational capacity building as a strategy to reduce racial health disparities. J Prim Prev. 2010;31(1-2):31-9.

60. Wallerstein NB, Yen IH, Syme SL. Integration of social epidemiology and community-engaged interventions to improve health equity. Am J Public Health. 2011;101(5):822-30. 
61. Behrman RE, Butler AS, Institute of Medicine (U.S.). Committee on understanding premature birth and assuring healthy outcomes. Preterm birth: causes, consequences, and prevention. Washington, DC: National Academies Press; 2007.
62. Lu MC, Kotelchuck M, Hogan V, Jones L, Wright K, Halfon $\mathrm{N}$. Closing the Black-White gap in birth outcomes: a lifecourse approach. Ethn Dis. Winter 2010;20(1 Suppl 2):S2-6276. 